\title{
Percepção dos alunos do curso técnico em desenvolvimento de sistemas após vivências com o método de ensino peer instruction
}

Perception of students of the technical course in systems development after experiences with the teaching method peer instruction

Percepción de los estudiantes del curso técnico em desarrollo de sistemas después de experiencias com el método de enseñanza traducción de la instrucción entre pares

\author{
Jessé Gonçalves Fonseca \\ ORCID: https://orcid.org/0000-0003-3297-5438 \\ Universidade Municipal de São Caetano do Sul, Brasil \\ jesse.fonseca01@etec.sp.gov.br \\ Carlos Alexandre Felício Brito \\ ORCID: https://orcid.org/0000-0002-0060-8644 \\ Universidade Municipal de São Caetano do Sul, Brasil \\ carlos.brito@prof.uscs.edu.br
}

\begin{abstract}
Resumo
O presente trabalho discute e apresenta resultados de um experimento realizado no componente de Algoritmos e Programação do Curso Técnico Profissionalizante em Desenvolvimento de Sistemas de uma escola pública, utilizando a metodologia ativa de aprendizagem Peer Instruction (Instrução por Pares). A prática docente tem como objetivo desenvolver a participação ativa e protagonista dos alunos durante as aulas de Algoritmos e Programação, através de um método de ensino ativo, no qual desenvolve os métodos colaborativos, permitindo a socialização dos saberes em um tempo reduzido, facilitando a formação necessário ao aluno do ensino técnico profissional, para que no futuro coloque em prática as suas competências, habilidades e atitudes. A interação rápida oferecida pelo Aplicativo Socrative, através das atividades diagnóstica, momento em que o docente identificará as lacunas de aprendizagens, facilitando a retomada dos conteúdos das bases tecnológicas durante o processo de ensino e aprendizagem. Nesta perspectiva, considera-se que alcançamos o Sucesso Escolar.
\end{abstract}

Palavras-chave: Aprendizagem; Instrução por pares; Algoritmos e programação.

\begin{abstract}
The present work discusses and presents results of an experiment carried out in the Algorithms and Programming component of the Professional Technical Course in Systems Development of a public school, using the active learning methodology Peer Instruction (Peer Instruction). The teaching practice aims to develop the active and protagonist participation of students during Algorithms and Programming classes, through an active teaching method, in which it develops collaborative methods, allowing the socialization of knowledge in a short time, facilitating training necessary for students of professional technical education, so that in the future they can put their skills, abilities and attitudes into practice. The quick interaction offered by the Socrative Application, through diagnostic activities, at which time the teacher will identify the learning gaps, facilitating the resumption of the contents of the technological bases during the teaching and learning process. In this perspective, it is considered that we have achieved School Success.
\end{abstract}

Keywords: Learning; Peer instruction; Algorithms and programming.

\section{Resumen}

El presente trabajo discute y presenta los resultados de un experimento realizado en el componente Algoritmos y Programación del Curso Técnico Profesional en Desarrollo de Sistemas de una escuela pública, utilizando la metodología de aprendizaje activo Peer Instruction (Peer Instruction). La práctica docente tiene como objetivo desarrollar la participación activa y protagónica de los estudiantes durante las clases de Algoritmos y Programación, a través de un método de enseñanza activo, en el que se desarrollan métodos colaborativos, permitiendo la socialización del conocimiento en poco tiempo, facilitando la formación necesaria para los estudiantes de técnica profesional. educación, para que en el futuro puedan poner en práctica sus habilidades, habilidades y actitudes. La rápida interacción que ofrece la Aplicación Socrativa, a través de actividades de diagnóstico, en cuyo momento el docente 
identificará las brechas de aprendizaje, facilitando la reanudación de los contenidos de las bases tecnológicas durante el proceso de enseñanza y aprendizaje. En esta perspectiva, se considera que hemos logrado el Éxito Escolar.

Palabras clave: Aprendizaje; Instrucción entre compañeros; Algoritmos y programación.

\section{Introdução}

$\mathrm{O}$ estudo das linguagens de programação de computadores tem como intuito capacitar os alunos a desenvolver programas e sistemas computadorizados que objetivam a resolução de problemas. Entretanto aprender a programar não é fácil e isto se reflete nos baixos níveis de assimilação experimentados por muitos alunos no componente curricular de Programação e Algoritmos do Curso Técnico em Desenvolvimento de Sistemas.

Esse cenário é reflexo da dificuldade no entendimento aliado ao desenvolvimento do raciocínio lógico, o que acaba acarretando a evasão nos cursos e baixo rendimento dos alunos no componente.

Para desenvolver o conhecimento e aprender a programar são requeridas competências relacionadas ao uso adequado do raciocínio lógico e matemático para resolução de problemas, configurando-se como um dos maiores desafios dos alunos (Barros \& Santos, 2018). As barreiras que dificultam o aprendizado de algoritmos têm diferentes origens e naturezas, compreendendo questões de ordem didática, afetiva e cognitiva (Raabe \& Silva, 2005).

Independente de qual for a origem das dificuldades é consenso entre os professores que atuam com algoritmos e programação de que elas existem e que estratégias de ensino diferentes precisam ser experimentadas (Bulcão, Campos Neto \& Moreira, 2017), visando a maximizar o aprendizado e motivar os estudantes a permanecerem no curso.

Vários estudos investigam as dificuldades de ensino e aprendizagem de algoritmos, propondo alternativas metodológicas ou instrumentais para auxiliar este processo.

Segundo Carvalho (2004), os professores devem diversificar suas as práticas professores, no intuito de torná-las lúdicas e dinâmicas permitindo a construção dos saberes. Desta maneira o aluno despertará sua condição de protagonista através do saber científico no uso dos métodos de ensino diversificados.

Sendo assim, é necessário identificar a percepção dos alunos após vivências com as metodologias ativas, verificar a eficácia, e se ocorre a participação ativa dos alunos durante o processo de ensino.

Outros estudos atribuem as dificuldades às prática docente utilizadas, muitas vezes pautadas no "treinamento intensivo" condicionadas em resoluções de exercícios (Motil \& Epstein, 2000; Perkins,1989).

Entre as várias construções metodológicas difundidas atualmente, as Metodologias Ativas de Aprendizagem têm conquistado prestígio entre as opções didáticas mais modernas, por formas de construção de conhecimento que inserem o aluno em posições de protagonismo, permitindo que as construções cognitivas estejam em consonância com as estruturas já construídas anteriormente. Entre tantas maneiras de se apresentar, algumas formas de Metodologias Ativas de Aprendizagem são: a aprendizagem cooperativa, a aprendizagem baseada em problemas, a aprendizagem entre pares (explorada neste artigo), os estudos de caso e as simulações.

Entre as similaridades, todas elas se baseiam no protagonismo do aluno e na sua participação direta, o que, por isso, promove a aprendizagem ativa, ou seja, é um processo que estimula a autoaprendizagem e facilita a educação continuada, pode ser, portanto, um meio para a dissimulação do pensamento algorítmico.

Um outro fator é a falta de motivação que é fortemente influenciada pela metodologia adotada. Borges (2000) destaca outras razões, como: dificuldade do estudante em desenvolver o raciocínio lógico, baixa capacidade de abstração, metodologias de ensino focadas no ensino da lógica, falta de acompanhamento individualizado do professor, entre outros.

Este último reforça o que Bloom (1984) já evidenciou em um estudo com alunos que receberam tutoria individual obtiveram um desempenho médio de dois desvios padrões (dois sigmas) acima do resultado médio, comparados a alunos que 
participaram de aulas expositivas para trinta alunos.

Diante das dificuldades de o professor em oferecer um acompanhamento individualizado com turmas de 30 ou mais alunos, a oportunidade de eles trabalharem em pares também pode ser vista como uma alternativa com potencial instigador e motivador a ser explorado e que vai ao encontro com os apontamentos de Borges (2000) e as conclusões de Bloom (1984).

Observando-se esta linha de pesquisa, Vygotsky (1984) destaca que as atividades realizadas em grupo oferecem muitas vantagens, que não estão disponíveis em ambientes individualizados de aprendizagem, como, por exemplo, a ajuda mútua. Nesse sentido, a atividade em pares deve ser bem pensada e ancorada em metodologias de ensino que tenham esse propósito.

Todavia, Kafai (2016) defende o movimento da participação entre alunos em ambientes computacionais no ensino da programação, considerando ser uma atividade social e criativa.

\section{Aprendizagem Significativa}

A aprendizagem é muito mais significativa no momento em que o novo conteúdo é incorporado às estruturas de conhecimento de um aluno e adquire significado para ele a partir da relação com seu conhecimento prévio.

Para o especialista em Psicologia Educacional David Ausubel, a aprendizagem significativa, pensada no contexto escolar, leva em conta a história do sujeito e ressalta o papel dos professores na proposição de situações que favoreçam a aprendizagem.

Para Jean Piaget (1896-1980) todo conhecimento somente é possível porque há outros anteriores.

De acordo com Ausubel, há duas condições para que a aprendizagem significativa ocorra: o conteúdo a ser ensinado deve ser potencialmente revelador e o estudante precisa estar disposto a relacionar o material de maneira consistente e não arbitrária.

Moreira (2012) enfatiza que não existe livro significativo, nem aula significativa, nem problema significativo, pois o significado está nas pessoas, não nos materiais.

Portanto, é preciso haver a predisposição para aprender, ou seja, para que haja uma aprendizagem significativa é indispensável que os alunos se predisponham a aprender significativamente.

No entanto, enquanto o conhecimento prévio diz respeito aos saberes que os alunos já possuem, os pré-requisitos constituem uma lista, muitas vezes arbitrária, de conteúdos e habilidades sem as quais, teoricamente, não seria possível seguir para o próximo para o conteúdo seguinte. Há dois problemas com o uso de pré-requisitos. O primeiro é excluir do processo educativo dos alunos que não dominam determinado tema. O segundo é que, em muitos casos, os pré-requisitos determinados pelo professor são aleatórios e não têm relação com o processo de aprendizagem.

A aprendizagem significativa somente é possível quando um novo conhecimento se relaciona de forma substantiva e não arbitrária a outro já existente. Para que essa relação ocorra, é preciso que exista uma predisposição para aprender. Ao mesmo tempo, é necessária uma situação de ensino potencialmente significativa, planejada pelo professor, que leve em conta o contexto no qual o estudante está inserido e o uso social do objeto a ser estudado.

(...) aprendizagem memorística $\mathrm{X}$ aprendizagem significativa e o processo avaliativo

Pode-se concluir que, quanto mais significativa e clara a aprendizagem se apresentar, maior será a sua funcionalidade para o aluno, tendo em vista que oferece mais possibilidades de interação com novas situações e conteúdo.

Imbuídos desses conceitos, propõe-se como solução para dificuldades de aprendizagem apresentadas neste artigo, as 
metodologias ativas de aprendizagem. Essas constituem-se como ferramentas que podem auxiliar o estudante em sua trajetória de aprendizagem que une as pontas entre os conhecimentos prévios e os objetivos propostos para uma determinada unidade de estudos, pois exploram a "problematização como estratégia de ensino e aprendizagem, com o objetivo de alcançar e motivar o aluno, pois diante do problema, ele se detém, examina, reflete, relaciona a sua história e passa a ressignificar suas descobertas" (Mitre et al., 2008).

Dessa forma, envolve os alunos por meio de atividades ou discussão em sala de aula, permitindo que a aprendizagem ocorra de maneira ativa quando o aluno interage com o assunto, enfatizando o pensamento de ordem superior (ouvindo, falando, escutando, perguntando, discutindo, fazendo e ensinando) e geralmente envolvendo trabalho em grupo (Barbosa; DE Moura, 2013; Berbel, 2011; Freeman et al., 2014; Giraffa; Müller, 2017; Vasconcelos et al., 2019).

A aprendizagem por pares caracteriza-se como uma metodologia onde a troca de experiências e conhecimentos entre os educandos é estimulada pelo professor. Diferentes estratégias podem ser exploradas para fomentar a interação, bem como a discussão e o debate acerca de determinado conceito ou assunto. Uma das metodologias que orientam o trabalho docente na promoção do aprendizado entre pares é o Peer Instruction - Instrução por pares.

\section{Método Peer Instruction: Instrução por Pares}

Conforme Mazur (1997), a metodologia Peer Instruction tem como objetivo tornar o processo de ensino e aprendizagem interativo, visando à interação por pares - por meio do desenvolvimento das competências socioemocionais, dentre elas a cooperação - e à realização do trabalho em equipe com a mediação de artefatos digitais, facilitando a prática docente. Durante a aplicação do método, é possível utilizar o Aplicativo Socrative, que oferece várias ferramentas lúdicas para o processo de aprendizagem.

Assim, conforme o autor Mazur (1997), o método ativo descrito em cinco fases:

$\checkmark \quad$ Fase 1 - Professor expõe um conceito específico.

$\checkmark \quad$ Fase 2 - Formação de equipes.

$\checkmark \quad$ Fase 3 - Aplicação de teste conceitual, pode ser respondido via Software aplicativo de quiz.

$\checkmark \quad$ Fase 4 - Professor avalia a resposta: até 30\% acertos (revisar conteúdo); entre 30\% e 70\% (alunos discutem a questão); mais de 70\% (professor explano sobre o conteúdo e próxima questão).

Para que a metodologia de ensino seja uma boa prática é necessário selecionar as questões que obtiveram resultados assertivos entre $35 \%$ e $70 \%$ de acertos. Caso a assertividade da correção seja inferior 35\%, o professor deverá apresentar novamente o conteúdo da base tecnológica, realizando a devolutiva da correção da atividade proposta.

Caso seja superior a 70\% de acertos, o professor poderá passar para um novo tópico de seu plano de aula.

Desta forma pode-se observar na Figura 1, um fluxograma que demosntra a aplicação do método Peer Instruction Instrução por Pares. 
Figura 1: Fluxograma do método Peer Instruction.

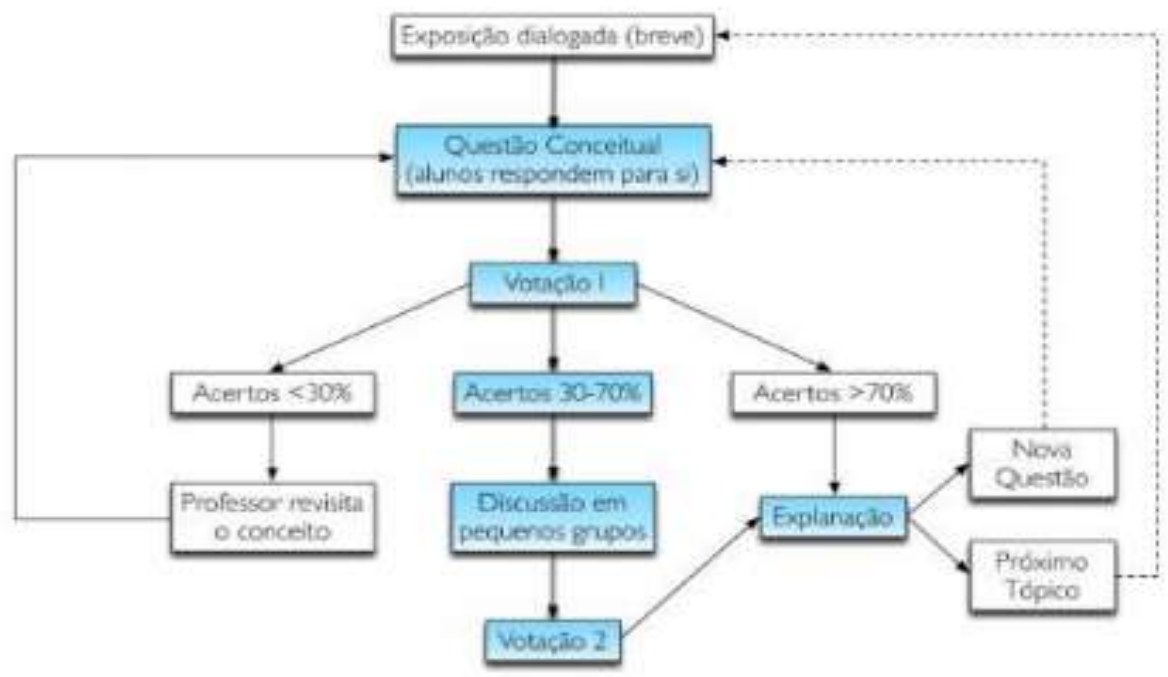

Fonte: Mazur \& Somer (1997, p.6)

\subsection{Aplicativo Socrative}

Para criar uma plataforma de aprendizagem centrado no aluno como agente ativo é necessário considerar que o ambiente deve prever não apenas apresentação de situações de aprendizagem, mas também, permitir ao aluno a criação de novas situações, lembrando que essa resolução pode ser social e não apenas individual.

O Socrative é um software que funciona baseado na internet, é gratuito e multiplataforma. Nele, professores podem criar salas de aula virtuais para acesso de modo interativo e simultâneo. Disponibiliza quatro tipos de atividades que podem ser elaboradas:

- Criar perguntas de saída, que nada mais são do que perguntas que servem para fazer um diagnóstico antes ou depois da aula sobre determinado assunto trabalhado com a turma, ou mesmo procurar saber se os alunos gostaram da metodologia usada durante a exposição do conteúdo.

- Há também a possibilidade de usar a ferramenta como um jogo, onde as equipes formadas por alunos são divididas e levadas a responder um questionário, a primeira equipe a finalizar o questionário, vence a disputa que na ferramenta se chama "corrida espacial".

- Outra forma de uso é propor que alunos escolham um tema para ser estudado e cada resposta dada pode ser avaliada pelos próprios alunos como forma de democratizar essa escolha.

- A última atividade disponível é a criação de questionários interativos, no qual os alunos respondem individualmente e o professor acompanha o desempenho dos mesmos.

A capacidade de elaborar questionários interativos dá ressignificação à forma como os alunos recebem o diagnóstico do ensino-aprendizagem e são avaliados.

O gerenciador de informações no caso o professor, efetua o cadastro no Website e cria uma sala de aula virtual de aprendizagem. Os exercícios (questões objetivas) podem ser acessada em qualquer host (Computador de mesa, tablets ou smarthphones), ou seja, qualquer dispositivo habilitado na rede mundial de computadores, obtendo as respostas em tempo real.

Segundo Moreira (1999), o aplicativo Socrative, além de consiste em um artefato digital que apoia o uso das metodologias ativas, torna'se em um sistema de gerenciamento de dados, tornando a estrutura de dados organizada para a 
inclusão de novos conteúdos, realizando a fusão dos conhecimentos prévios estabelecidos na estrutura cognitiva, com os novos conceitos, tornando-se uma aprendizagens significativas.

Uma característica fundamental que o Aplicativo Socrative oferece, é o feedback imediato, que torna essencial para o Método Ativo Peer Instruction - Instrução por pares, permitindo a verificação das lacunas de aprendizagens durante as fases das aulas, tornando o método eficaz a assimilação de novas aprendizagens.

\subsection{O Ensino de Programação e Algoritmos no Curso Técnico em Desenvolvimento de Sistemas}

As competências solicitadas para desenvolver a programação de computadores, está vinculado ao uso raciocínio lógico, matemático e abstração para resolução de problemas, configuram-se como um dos maiores desafios que enfrentam os alunos ingressantes (Brandão, 2014).

O componente curricular de Programação e Algoritmos é o conceito inicial para qualquer curso de Desenvolvimento de Sistemas.

Neste curso, temos uma grande problemática na questão relacionada a evasão escolar. Muitos alunos apresentam lacunas de aprendizagem, em conceitos iniciais, prejudicando o andamento das turmas.

Após análise das atas dos conselhos de classe intermediário, final da unidade escolar, foram diagnosticados os baixos desempenhos dos alunos da turma do componente de Programação e Algoritmos. Conforme os dados apresentados as turmas dos segundos módulos: matutino e noturno apresentam 16,67\% e 15,39\%, ou seja, 30 alunos matriculados 6 foram evadidos no período matutino, já no período noturno 33 alunos matriculados 6 foram evadidos.

Constatamos que o percentual de perda é alto. A análise mostra a perda escolar nos cursos de Desenvolvimento de Sistemas nos períodos matutino e noturno, os quais apresentaram uma perda acima de $15 \%$.

Tabela 1: Tabela de saldo de alunos (2018) Etec de Mauá - Sede.

\begin{tabular}{|c|c|c|c|c|c|c|}
\hline Curso & $\begin{array}{r}\text { Entrada } \\
1^{\circ}\end{array}$ & stre/2018 & $\begin{array}{l}\text { Entrada } \\
2^{\circ} \text { Semestre/2018 }\end{array}$ & & Perda & \begin{tabular}{|l|}
$\%$ \\
Comparativa
\end{tabular} \\
\hline \multirow{3}{*}{$\begin{array}{l}\text { Desenvolvimento } \\
\text { Sistemas (manhã) }\end{array}$} & $1^{\circ}$ Módulo & 40 & $2^{\circ}$ Módulo & 35 & 5 & $12,50 \%$ \\
\hline & de $\overline{2^{\circ} \text { Módulo }}$ & 36 & $3^{\circ}$ Módulo & 30 & 6 & $16,67 \%$ \\
\hline & $3^{\circ}$ Módulo & 30 & $\begin{array}{ll}\text { Saída } & 1^{\circ} \\
\text { Semestre/2018 }\end{array}$ & 26 & 4 & $13,34 \%$ \\
\hline \multirow{3}{*}{$\begin{array}{l}\text { Desenvolvimento } \\
\text { Sistemas (noite) }\end{array}$} & $1^{\circ}$ Módulo & 40 & $2^{\circ}$ Módulo & 35 & 5 & $10,26 \%$ \\
\hline & de $\longdiv { 2 ^ { \circ } \text { Módulo } }$ & 39 & $3^{\circ}$ Módulo & 33 & 6 & $15,39 \%$ \\
\hline & $3^{\circ}$ Módulo & 26 & $\begin{array}{ll}\text { Saída } & 1^{\circ} \\
\text { Semestre/2018 }\end{array}$ & 23 & 3 & $11,54 \%$ \\
\hline
\end{tabular}

Fonte: PPG Escola Técnica.

Como soluções, propõe-se a utilização de metodologias ativas de aprendizagem que promovem a centralidade no aluno e priorizam a aprendizagem colaborativa por meio de trabalhos em grupo (Moran, 2019); 


\section{Metodologia}

Esta pesquisa é resultado da aplicação da boa prática Peer Instruciton - Instrução por pares. A pesquisa foi realizada por 32 alunos do primeiro módulo. Após a boa prática, foi aplicado um instrumento de pesquisa pelo Google Forms, como objetivo de coletar uma amostra de estudo e em seguida realizar a análise inferência estatísticas. Segue as fases do desenvolvimento da prática docente:

Fase 1 - Professor expõe um conceito específico. O tema trabalhado foi Regras de Inferência, o professor realizou-se um planejamento sobre o que se pretende alcançar: "Antes", "Durante" e "Após" a aplicação da metodologia (Tabela 1).

Tabela 2: Planejamento dos objetivos de aplicação da metodologia.

\begin{tabular}{l|l|l}
\hline Antes & Durante & Após \\
\hline $\begin{array}{l}\text { motivar para a leitura } \\
\text { ativar conhecimentos prévios } \\
\text { definir objetivo de leitura }\end{array}$ & $\begin{array}{l}\text { seleção } \\
\text { direcionar a atenção } \\
\text { automonitorar, } \\
\text { autoavaliar, } \\
\text { ativar do conhecimento prévio }\end{array}$ & $\begin{array}{l}\text { sumarizar, } \\
\text { identificar a ideia principal, } \\
\text { responder perguntas }\end{array}$ \\
\hline
\end{tabular}

Fonte: Adaptado de Solé (1998)

Fase 2 - Formação de equipes - Fase inicial realizada no laboratório de Informática com o DataShow na projeção de slides.

Fase 3 - Aplicação de teste conceitual, pode ser respondido via Aplicativo Socrative aplicativo de quis. Etapa realizada no laboratório de Informática com apoio ao Aplicativo Socrative, com aplicação de um quis para os alunos desenvolvessem o exercício de forma individual e depois posteriormente em pares.

Fase 4 - Professor avalia a resposta: até 30\% acertos (revisar conteúdo); entre 30\% e 70\% (alunos interagem sobre o assunto); mais de 70\% (professor explano sobre o conteúdo e próxima questão). questão sobre o mesmo conceito ou passar ao próximo tópico da aula, voltando ao primeiro passo. Momento de total interação da turma, sendo individual ou em pares,

Fase 5 - Validação da metodologia aplicada - Foi criado um formulário para coletar as narrativas discentes dos alunos sobre a prática docente aplicada.

Ao dar início da aula, o professor aplicou o método de ensino Peer Instruction, em seguida foi realizado um momento de revisão dos conteúdos da base tecnológica. Após a revisão da matéria os alunos tiveram acesso ao aplicativo Socrative, no qual realizaram ações de ambientação da plataforma. Logo em seguinte, os alunos realizaram uma atividade com questões objetivas com múltiplas escolha para os alunos, no qual foi estipulado 2 minutos para responderem a mesma de forma individual.

Ressaltamos que todas as 10 questões foram resolvidas.

Foram entrevistados 20 alunos. O questionário em se no estudo de LASRY et. al (2008), com três opções: de respostas: concordo, concordo parcialmente e discordo.

\section{Resultados e Discussões}

Os resultados apresentados na pesquisa mostram as percepções dos alunos do Curso Técnico em Desenvolvimento de Sistemas. Para a coleta dos dados foi aplicado um instrumento de pesquisa em que 32 alunos do Curso Técnico em Desenvolvimento de Sistemas responderam a pesquisa após a plicação do método de ensino. O Gráfico 1, é a representação 
Research, Society and Development, v. 10, n. 3, e10710312382, 2021

(CC BY 4.0) | ISSN 2525-3409 | DOI: http://dx.doi.org/10.33448/rsd-v10i3.12382

dos dados da Metodologia Aplicada em Sala de Aula. Constatou-se que 97\% dos alunos concorda com a aplicação do método ativo, $3 \%$ não aderiram o método inovador.

Gráfico 1: Metodologias aplicadas em aula.

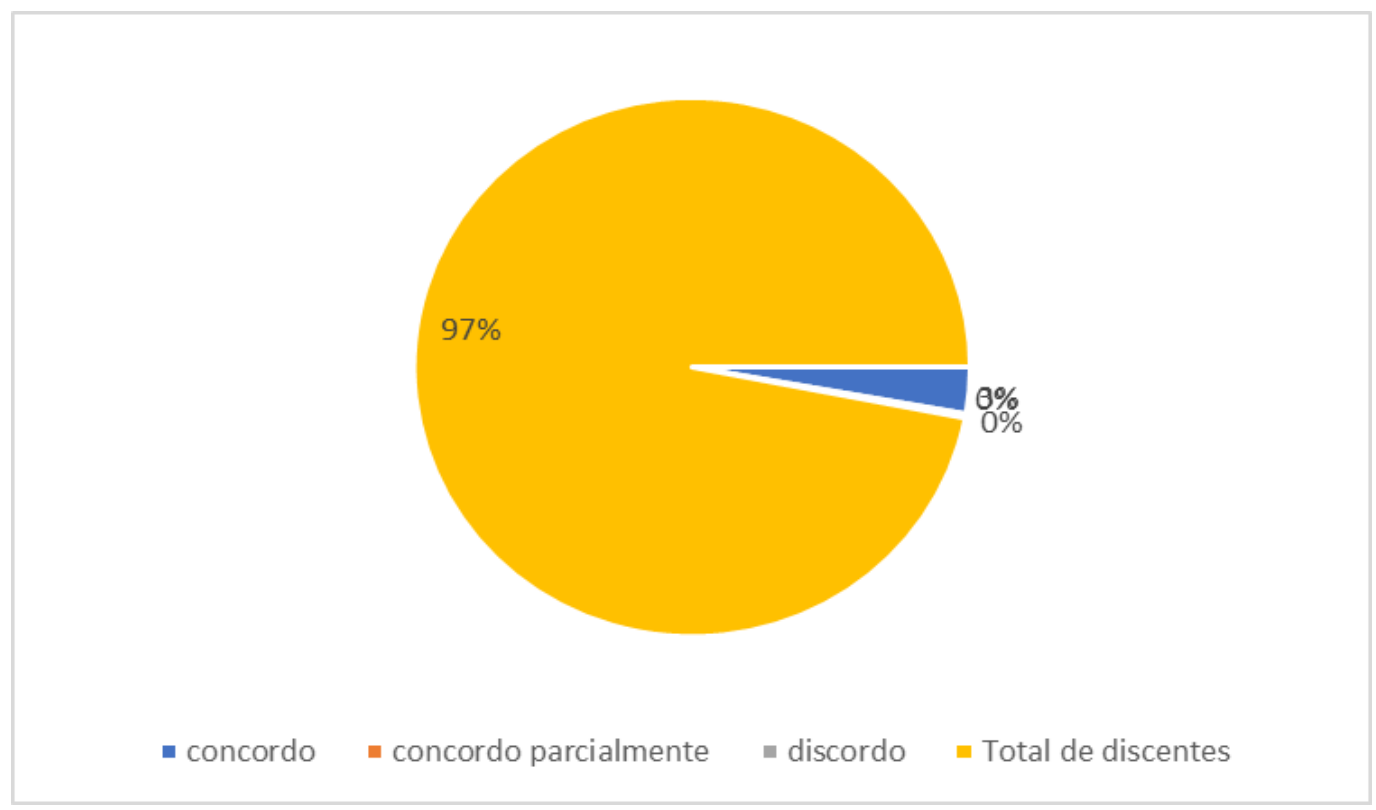

Fonte: Arquivo Pessoal.

O Gráfico 2, demonstra sobre o processo de Instrução por Pares, ou seja, o momento de Discussão em Grupo. Constatou-se $86 \%$ diz que concorda que a discussão em grupo facilita bastante na resolução dos problemas e $14 \%$ concorda.

Gráfico 2: Discussão em Grupo.

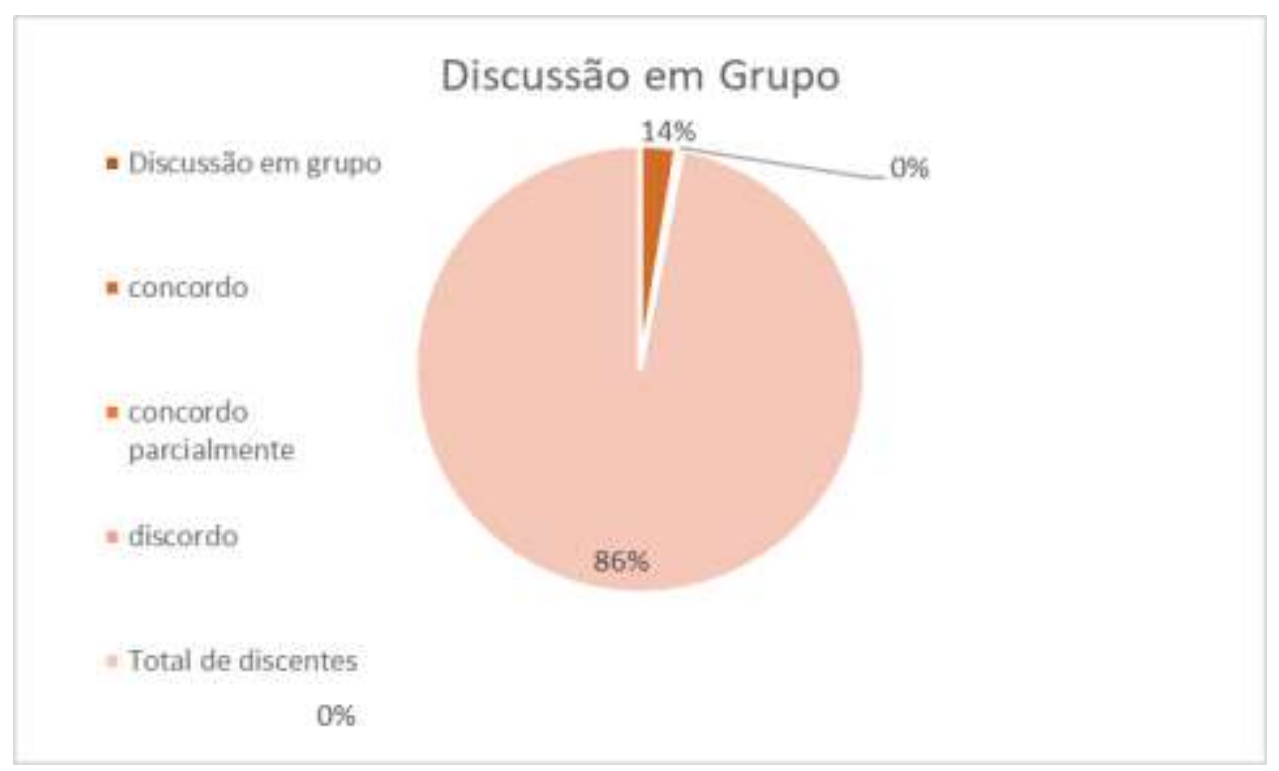

Fonte: Arquivo Pessoal.

O Gráfico 3, refere-se sobre a estratégia de abordar o conteúdo programático do componente curricular. Constatou-se que $92 \%$ concorda e $32 \%$ concorda parcialmente e $8 \%$ discorda. 
Research, Society and Development, v. 10, n. 3, e10710312382, 2021

(CC BY 4.0) | ISSN 2525-3409 | DOI: http://dx.doi.org/10.33448/rsd-v10i3.12382

Gráfico 3: Forma de abordar o conteúdo.

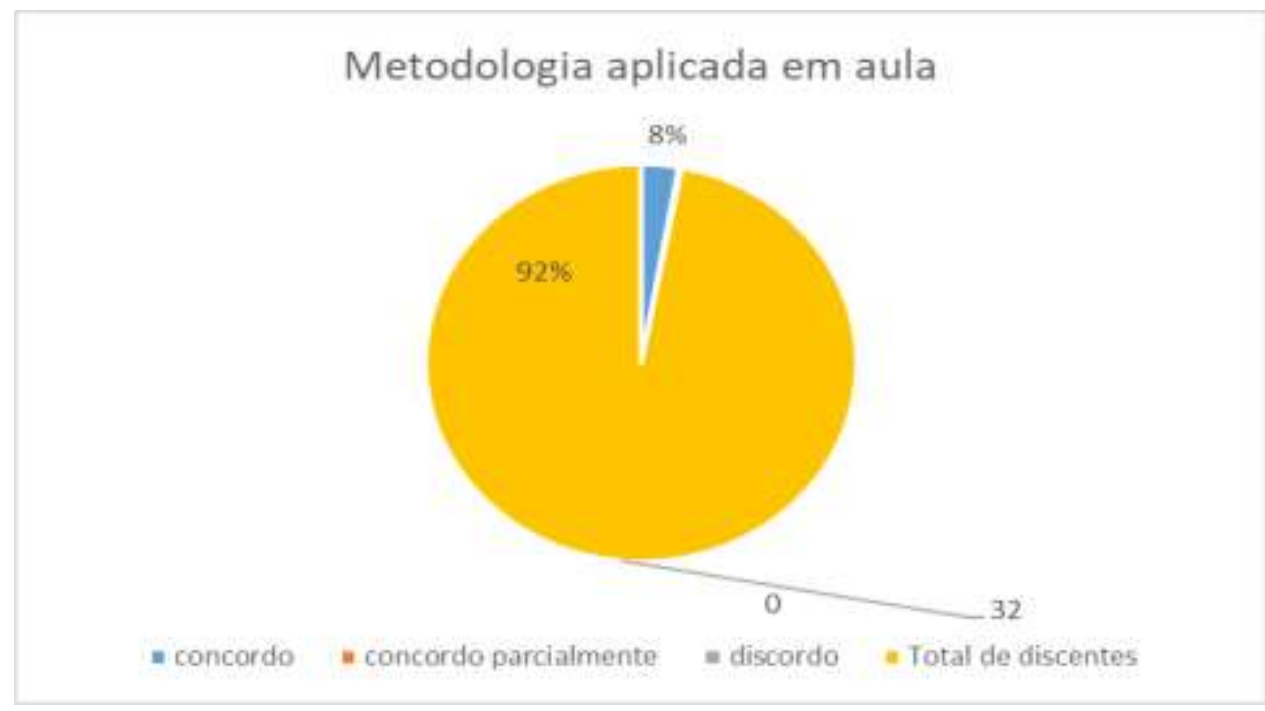

Fonte: Arquivo Pessoal.

O Gráfico 4, refere-se sobre o processo de resolução de exercícios. Constatou-se que $73 \%$ concorda, $14 \%$ concorda parcialmente e apenas $5 \%$ discorda.

Gráfico 4: Resolução dos exercícios.

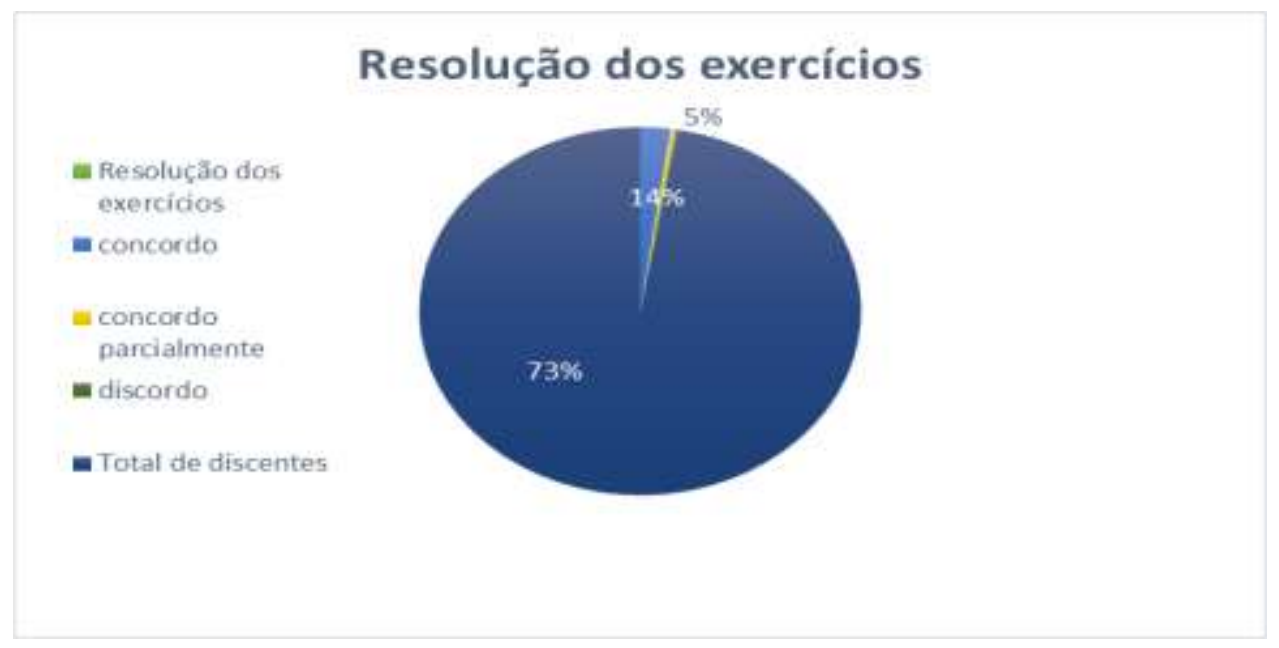

Fonte: Arquivo Pessoal

O Gráfico 5, representa a avaliação da metodologia aplicada. Constatou-se 52\% diz que foi discutir questões com os colegas, $10 \%$ relata que se obteve mais participação e atividades dos alunos e $38 \%$ fala sobre o uso das Tecnologias Digitais de Informação e Comunicação em apoio as metodologias ativas de aprendizagem. 
Research, Society and Development, v. 10, n. 3, e10710312382, 2021

(CC BY 4.0) | ISSN 2525-3409 | DOI: http://dx.doi.org/10.33448/rsd-v10i3.12382

Gráfico 5: Avaliação da metodologia.

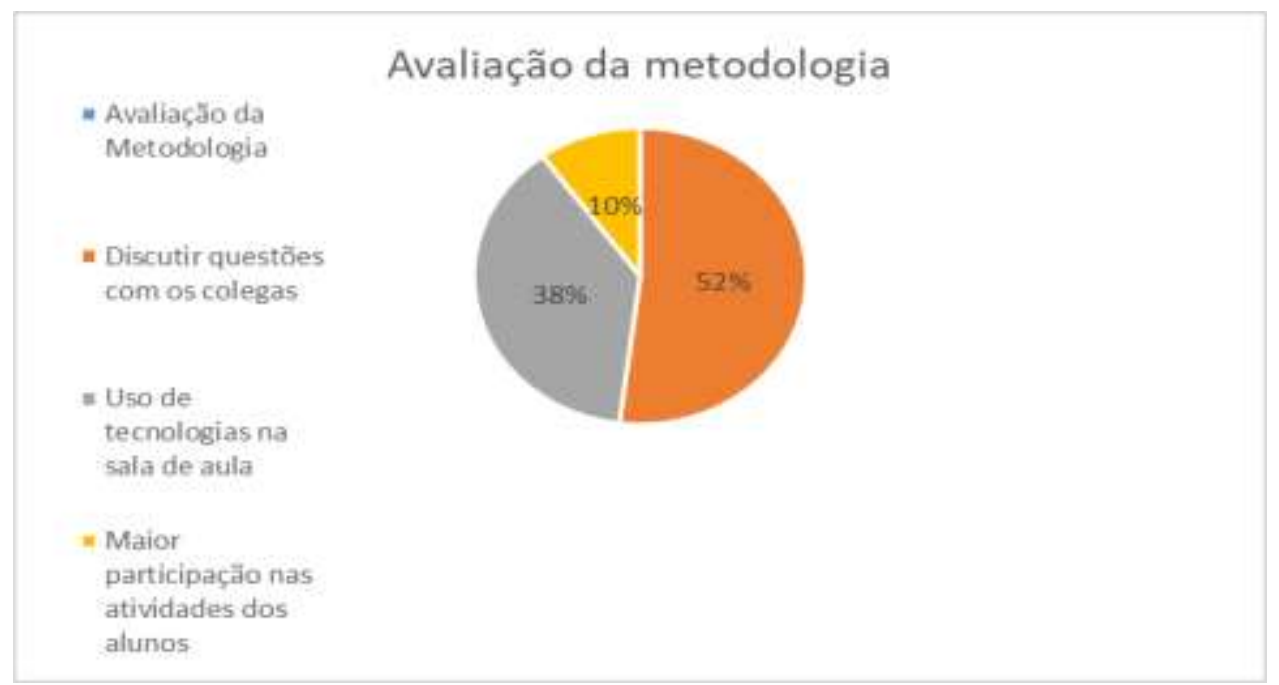

Fonte: Arquivo Pessoal

O Gráfico 6, o mesmo está realizado ao Tempo de devolutiva das atividades. Constatou-se que 52\%, responde em menor de 15 minutos, $38 \%$ leva entre 15 a 30 minutos e $10 \%$ demora entre 30 a 45 minutos.

Gráfico 6: Tempo.

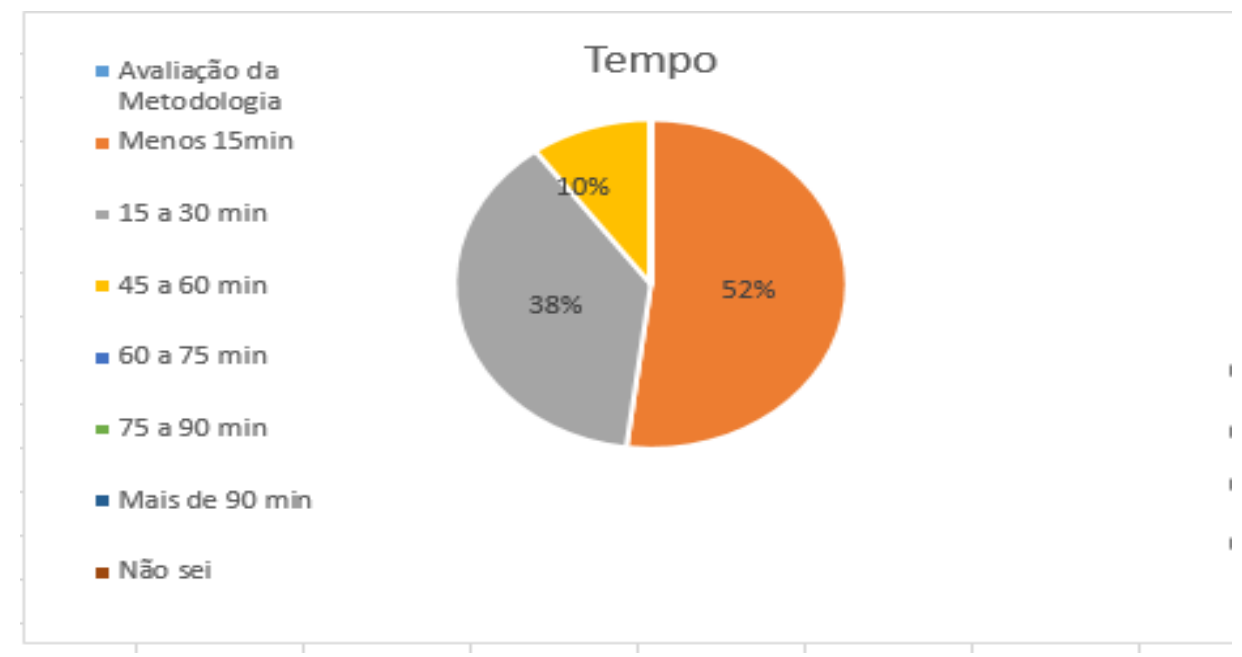

Fonte: Arquivo Pessoal

O Gráfico 7, consiste na comparação das metodologias de ensino, tradicional ou a aplicada na pesquisa. Constatou-se que $45 \%$ acha a metodologia aplicada muito bom, 30\% regular, $25 \%$ bom e nenhum aluno considera insatisfatório a metodologia ativas de aprendizagem aplicada. 
Gráfico 7: Comparação entre a Metodologia Tradicional e a Metodologia Aplicada.

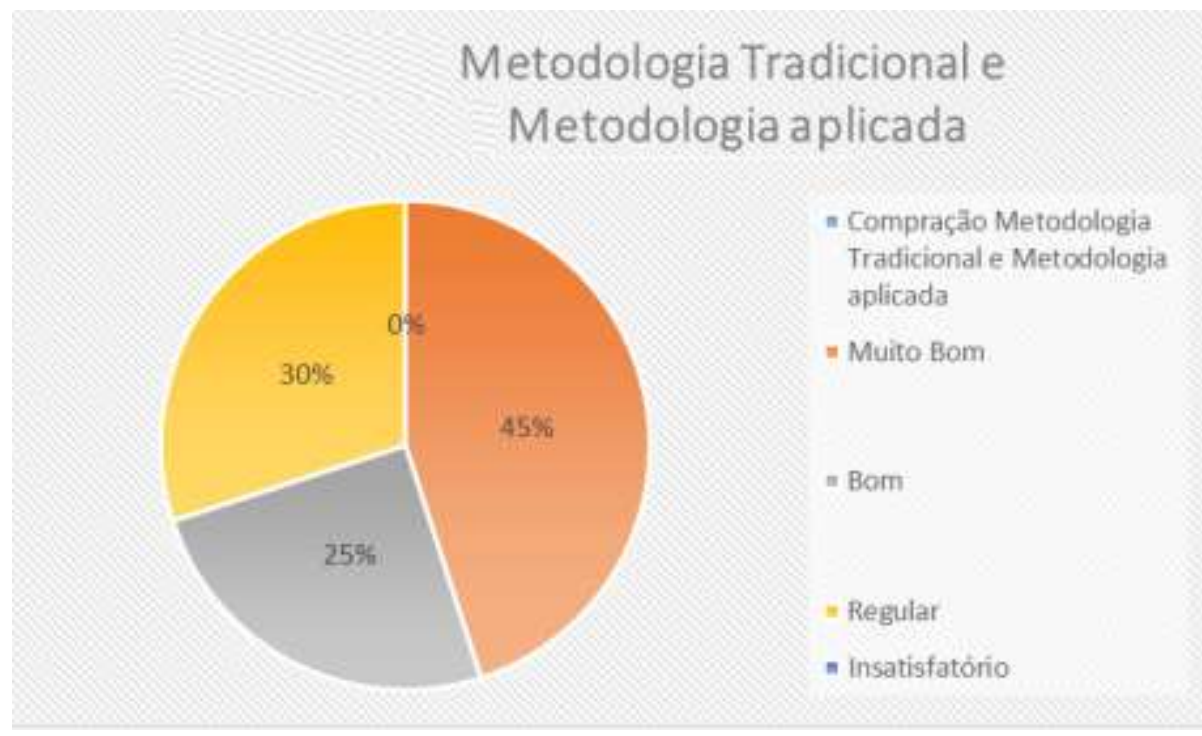

Fonte: Arquivo Pessoal

No instrumento de pesquisa além das questões de múltipla escolha, também haviam duas questões dissertativas para os alunos redigissem suas narrativas sobre as vivências do método de ensino.

\section{Considerações Finais}

Aprender a programar constitui-se de uma tarefa complexa que inclui: adquirir habilidade para resolução de problemas, aprender a sintaxe e a semântica de uma linguagem de programação, utilizar um ambiente de desenvolvimento de programação e realizar testes e depuração de programas. É preciso identificar detalhadamente em quais dessas tarefas existem as lacunas que impedem ou dificultam o aprendizado.

No intuito de encontrar essas lacunas de aprendizagem se faz necessário considerar concepções mais sistêmicas e complexas, no que se refere à construção dos saberes.

Com a intervenção pedagógica constatou-se a eficácia do método ativo, e a satisfação dos alunos após a aplicação do método Peer Instruction - Instrução por Pares, obtendo ótimos resultados de desempenho com o engajamento dos alunos da turma durante a atividade. Com a aplicação método Peer Instruction - Instrução por Pares, proporcionaram aos alunos assimilarem os conteúdos de estrutura de dados em um menor espaço de tempo, melhorando o desempenho nas aulas de Programação e Algoritmos evidenciando a aceitação do método ativo de aprendizagem.

O envolvimento colaborativo da turma nessa dinâmica de interação por pares foi satisfatório. Neste momento de aprendizado o professor através dos artefatos digital - Aplicativo Socrative, tem a possibilidade de identificar as lacunas de aprendizagem e suprir a necessidade da turma.

Vygotsky (1998) afirma que a interação social desempenha uma função chave no desenvolvimento cognitivo e é mediante atividades que intensifiquem esse conceito, que a aprendizagem colaborativa pode contribuir de forma positiva para atingir objetivos comuns.

Durante a aplicação do Método Peer Instruction - Instrução por Pares, os resultados foram significativos, os alunos assumiram o papel de protagonista durante a aplicação do método ativo.

Acredita-se que com os resultados significativos, gerados pela experiência relatada, possa sinalizar novas perspectivas de práticas e indicar novas direções para o estudo e investigação no ensino de Programação e Algoritmos, alcançando o Sucesso Escolar. 
Research, Society and Development, v. 10, n. 3, e10710312382, 2021

(CC BY 4.0) | ISSN 2525-3409 | DOI: http://dx.doi.org/10.33448/rsd-v10i3.12382

\section{Referências}

Barbosa, E. F., \& Moura, D. G. (2013) Metodologias ativas de aprendizagem na educação profissional e tecnológica. Boletim Técnico do Senac, 39(2), 48-67. http://www.bts.senac.br/index.php/bts/article/view/349/333.

Barros, D. De S. A., \& Santos, J. R. A. (2018) Técnicas de estudo e gestão do tempo no auxílio a aprendizagem de fundamentos de algoritmos e lógica aplicada a computação. CIMATech, 1(5).

Berbel, N. (2011) As metodologias ativas e a promoção da autonomia de estudantes. Ciências Sociais e Humanas, 32(1), 25-40.

Bloom, B. S. (1984). The 2 Sigma Problem: The search for methods of group instruction as effective as one-to-one tutoring". In: Educational Researcher. 416

Borges, M. \& Augusto F. (2000). “Avaliação de uma metodologia alternativa para a aprendizagem de programação”. VIII Workshop de Educação em Computação - WEI. Curitiba.

Brandão Junior, J. A., \& Neves, J. M. S. (2014) “Aplicação da Metodologia "Peer Instruction” em um curso técnico em Informática". IX Workshop de PósGraduação e Pesquisa do Centro Paula Souza. Estratégias Globais e Sistemas Produtivos Brasileiros.

Bulcão, J. D. S. B., Campos Neto, E. B., \& Moreira, K. C. (2017) Mapping on the teaching of algorithms and computational logic in the degree courses of computer science and computing in higher education institutions in Brazil. In: CEUR Workshop Periódico científico acadêmicos, Ctrl+E 2017 - Anais do II Congresso sobre Tecnologias na Educacao, Periódico científico acadêmicos of the 2nd Congress on Technology in Education, Ctrl + E 2017. Natal.

Carvalho, A. M. P. (2004). Critérios estruturantes para o Ensino de Ciências. In:Carvalho, A. M. P. Ensino de Ciências - Unindo a Pesquisa e a Prática. São Paulo:Pioneira Thomson Learning.

Freeman, S. et al. (2014) Active learning increases student performance in science, engineering, and mathematics. In: Proceedings of the National Academy of Sciences, 111(23), 8410-8415.

Giraffa, L. M. M., \& Müller, L. (2017) Metodologia baseada em sala de Aula invertida e Resolução de Problemas relacionado ao cotidiano dos estudantes. Brazil, South America.

Mazur, E., \& Somers, M. D. (1997) Peer instruction: A user's manual. Upper Saddle River, N.J. Prentice Hall, 253.

Mitre, S. M. et al. (2008) Metodologias ativas de ensino-aprendizagem na formação profissional em saúde: debates atuais. Ciênc. saúde coletiva. 13(2), 21332144. http://dx.doi.org/10.1590/S1413-81232008000900018.

Moran, J. Metodologias Ativas de bolso: Como os alunos podem aprender de forma ativa, simplificada e profunda. ditora do Brasil. 2019 -- (Arco 43)

Moreira, M. A. (1999). Aprendizagem significativa. Editora Universidade de Brasília.

Moreira, M. (1983) Uma abordagem cognitivista ao ensino da Física: a teoria da aprendizagem de David Ausubel como sistema de referência para a organização do ensino de ciências. Ed. UFRGS.

Raabe, A. L. A., \& Silva, J. M. C. Da. (2005) Um ambiente para atendimento as dificuldades de aprendizagem de algoritmos. In: XIII Workshop de Educação em Computação.

Sole, I. (1998). Estratégias de leitura. (6a ed.), Artmed, 1998.

Vasconcelos, A. C. et al. (2019) As estratégias de ensino por meio das metodologias ativas/Teaching strategies through active methodologies. Brazilian Journal of Development, 5(5), 3945-3952.

Vygotsky, Lev S. A. (1998) Formação Social da Mente. Martins Fontes. 190p. 